\author{
Giovanni D'Andrea \\ Franco Granella \\ Morena Cataldini \\ Flavio Verdelli \\ Tiziana Balbi
}

\section{GABA and glutamate in migraine}

G. D'Andrea (更) • F. Verdelli • T. Balbi Headache and Related Disorders Center, Pathology Unit, Este-Monselice Hospital, Este-Monselice (PD), Italy e-mail: giovinavi@libero.it Tel.: +39-0429-618421

Fax: +39-0429-618532

F. Granella

Institute of Neurology,

University of Parma, Parma, Italy

M. Cataldini

Department of Neurology,

Este-Monselice Hospital,

Este-Monselice (PD), Italy

\begin{abstract}
GABA and glutamic acid are the main inhibitory and excitatory neurotransmitters of central nervous system. Among other functions they modulate the pain threshold in the CNS. For this reason it has been hypothesized that anomalies of GABA and glutamate turn-over may play a role in migraine pathogenesis. In this review are discussed the evidences in favour of this hypothesis. A derangement of GABA may be an important factor in the occurrence of migraine attacks and their recurrence, whereas high level of glutamic acid may represent a biochemical marker of the neuronal hyperexcitability that may be the underlying
\end{abstract}

cause of the aura. The pharmacological modulation of metabolism of both neurotransmitters is a promising approach to improve migraine therapy. In particular the studies presented here suggest that gabaergic drugs may be useful in migraine without aura, antiglutamatergic drugs are indicated to treat migraine with aura.

Key words GABA • Glutamic acid • Migraine with and without aura . Migraine pathogenesis

\section{Introduction}

Migraine is a pathological condition characterised by crises of cephalic pain, at times accompanied by transient neurological and autonomic signs. Migraine attacks result from a complex cascade of events that initiate probably in the limbic structures and afterward spread to the cortex. Cortical spreading depression (SD), the neuronal event that is believed to cause the aura [1], may contribute to the activation of primary afferent fibres of trigeminal ganglion which innervate the meningeal vessels [2]. This activation may cause the release of vasoactive peptides such as substance $\mathrm{P}$, neurokinin $\mathrm{A}$ and calcitonin gene-related peptide in the trigeminal vascular bed $[3,4]$. The abnormal synthesis of nitric oxide (NO) and vasodilation, ultimate events that cause the migraine attacks, may be related to the stimulation of endothelium and platelets by these vascular peptides [5, 6]. The pain sensation travels through the fibre endings of primary trigeminal afferents stretched on the vessel wall stimulated by NO to the trigeminal nucleus caudalis (TNC) [7]. In the TNC, the nociceptive signal is modulated by interneurons and descending inhibitory systems (serotoninergic and noradrenenergic) [8]. From there, the stimulus travels to the ventrobasal, posterior and medial thalamus nuclei and, as final destination, to the limbic and sensory cortex [9].

Gamma-aminobutyric acid (GABA) and glutamate (Glu) are, respectively, the main inhibitory and excitatory neurotransmitters of the central nervous system (CNS) that modulate the neuronal excitability and pain threshold at many hierarchical levels of brain and spinal cord [10]. 
Anomalies of metabolism or release of GABA and/or Glu, possibly genetically determined, may be the predisposing pathophysiogical conditions that determine the occurrence and the frequency of migraine attacks [11]. This hypothesis is supported by anatomical, biochemical and pharmacological evidence exposed in this survey.

\section{GABA and migraine}

GABA is a neutral inhibitory aminoacid widely distributed throughout the $\mathrm{CNS}$, which binds to $\mathrm{GABA}_{\mathrm{A}}$ and possibly $\mathrm{GABA}_{B}$ receptors. $\mathrm{GABA}_{A}$ receptor is a complex of five peptide chains that form a transmembrane chloride ion channel. GABAA $_{A}$ receptor has specific sites for GABA binding and can be modulated by substances such as picrotoxin, barbiturates, bendodiazepines and anaesthetic steroids [12]. $\mathrm{GABA}_{\mathrm{B}}$ receptors are coupled to calcium or potassium ion channels via GPT binding proteins [13]. At spinal and trigeminonuclear levels GABA, released from the interneurons located in the superficial spinal dorsal horn (lamina I, II), reduces the excitability of nociceptive neurons through the stimulation of $\mathrm{GABA}_{\mathrm{A}}$ and $\mathrm{GABA}_{\mathrm{B}}$ receptors, mainly located on presynaptic terminals and possibly mediating presynaptic inhibition [14]. Pharmacological evidence suggests that GABA receptors play a role in the regulation of pain threshold in the TNC. In addition, GABA regulates cortical functions by circuits that modulate the activity of NMDA receptors post-synaptically [15].

In 1975, Welch et al. [16] showed that GABA levels in the cerebrospinal fluid (CSF), not detectable in tension-type headache (TTH) or in migraine during headache-free periods, increased during migraine attacks. They suggested that the metabolism of GABA is deranged in migraine [16]. In a second biochemical study, GABA was measured in the platelets of 19 migraine patients, 27 chronic tension-type headache $(\mathrm{CTH})$ patients and 21 control subjects [17]. The GABA levels in platelets were similar in migraine patients (during headache-free periods) and controls, whereas they were significantly elevated in $\mathrm{CTH}$ patients [17]. In another study, GABA was measured in the saliva of a large group of patients with migraine without aura (MO), both between and during attacks, in TTH patients and in controls [18]. The GABA saliva levels were high during MO attacks in comparison to interictal periods and to control subjects [18]. It is possible that the increase of GABA metabolism may be a compensatory beneficial process to limit migraine attacks and other primary headaches.

This hypothesis seems to be confirmed by pharmacological evidence. Valproate (2-propylpentanoic acid), a branched-chain fatty acid used in the treatment of several seizure types, reduced the frequency and severity of sponta- neous migraine attacks in randomized controlled trials [19-21]. The effective dosage of valproate varies from 500 to $1000 \mathrm{mg}$ daily, the highest dose being the most effective [22]. The effectiveness of valproate in migraine treatment is probably related to the inhibition of GABA aminotransaminase and to the activation of glutamic acid decarboxylase [19]. These enzymes block the catabolism and increase the synthesis of the neurotransmitter, respectively. Consequently, there is an increase of GABA availability in the gabaergic synaptic cleft and an enhancement of the relative inhibitory neurotransmission [19]. It is possible that the usefulness of valproate in the treatment of chronic daily headache derives from the same mechanism of action [23].

Gabapentin is a new antiepileptic drug that may increase brain GABA levels. In one randomised, double-blind, placebo-controlled trial, 63 migraine patients were treated with a $1200-\mathrm{mg} /$ day final dose of gabapentin. At the end of treatment, about half of the patients had a significant reduction in frequency and severity of their migraine attacks [24].

\section{Excitatory aminoacids and migraine}

Glutamic and aspartic (Asp) acids are CNS excitatory neurotransmitters. In the brain, Glu and and Asp are taken up from the circulation or directly synthesized and catabolized in the neurons and glia. Glu and Asp may be involved in migraine pathogenesis, since an abnormal release of glutamate causes neuronal hyperexcitability and may be essential in the propagation of SD, the supposed pathophysiological process of the aura $[25,26]$. Some biochemical and pharmacological evidence in favour of this hypothesis is presented.

Currently, it is not possible to study "in vivo" Glu and Asp metabolism in the CNS. Platelets are considered a good neuronal model for studying Glu and Asp metabolism. In fact platelets, like neurons and glia, synthesize and take up Glu from the blood, store it in the dense organelles and release this aminoacid with the same calcium-dependent mechanism of neurons [27]. Platelet levels of Glu and Asp were measured in patients with migraine with aura (MA) or MO and in control subjects in two studies [28, 29]. Both studies showed that platelet Glu and Asp levels are significantly higher in MA sufferers, both during headache-free periods and even more during attacks, in comparison to $\mathrm{MO}$ patients and control subjects. If these anomalies are shared by the neurons of MA sufferers, elevated amounts of excitatory aminoacids are available and may be released upon stimulation [28, 29].

Lamotrigine (6-[2,3-dichlorophenyl]-1,2,3 triazine-3,5diamine) is an antiepileptic drug for the treatment of partial and generalized epilepsies. It acts by blocking voltage-sen- 
sitive sodium channels, leading to the inhibition of neuronal release of Glu [30, 31]. The consequent reduced excitatory neurotrasmission may be beneficial in the prevention of migraine attacks.

Lamotrigine has been used as a prophylactic drug in $\mathrm{MO}$ and MA sufferers in three studies [32-34]. In the first study, a 3-month double-blind, randomised, parallel-groups trial mainly concerning MO sufferers, a dose of $200 \mathrm{mg}$ /day gave negative results [32]. This study suggests that lamotrigine is ineffective in the prophylactic treatment of MO. The aim of the other two open pilot trials $[33,34]$ was to treat only MA patients. Lamotrigine was effective in reducing the number of attacks in patients with frequent MA attacks. In the majority of patients, aura completely disappeared. The useful dose was 50-100 mg daily, lower than that used as antiepileptic treatment [33, 34]. Another antiglutamatergic drug, ketamine (given intranasally at the dosage of $25 \mathrm{mg}$ ) reduced the severity and duration of disabling auras in 5 of 11 patients affected by familial hemiplegic migraine [35], offering, for the first time, a possible treatment option for severe and prolonged aura.

\section{Conclusions}

Biochemical and pharmacological evidence suggests that GABA and Glu play a significant role in migraine pathogenesis. The pharmacological modulation of metabolism of both neurotransmitters is a promising approach to improve migraine therapy. In particular, the studies presented here suggest that gabaergic drugs may be useful in MO and in chronic daily headache, whereas antiglutamatergic drugs are indicated to treat MA.

\section{References}

1. Lauritzen M, Olesen J (1984) Regional cerebral blood flow during migraine attacks by xenon- 133 inhalation and emission tomography. Brain 107:447-461

2. Lauritzen M, Hansen AK, Kronber D, Wieloch T (1990) Cortical spreading depression is associated with arachidonic acid accumulation and preservation of energy charge. J Cereb Flow Metab 10:15-122

3. Buzzi MG, Carter WB, Shimizu T, Heath H, Moskowitz MA (1991) Dihydroergotamine and sumatriptan attenuate levels of CGRP in plasma in rat sagittal sinus during electrical stimulation of trigeminal ganglion. Neuropharmacology 30:1193-1200

4. Goadsby PJ, Edvinson L (1993) The trigeminovascular system and migraine: studies characterizing cerebrovascular and neuropeptide changes seen in humans and cats. Ann Neurol 33:48-56

5. D'Andrea G, Toldo M, Cortellazzo S, Ferro Milone F (1982) Platelet activity in migraine. Headache 22:207-212

6. Thomsen LL, Olesen J (2000) Nitric oxide involvement in migraine. In: Olesen J, Tfelt Hansen P, Welch KMA (eds) The headaches, 2nd edn. Lippincott Williams Wilkins, Philadelphia, pp 325-330
7. Mayberg MA, Langer RS, Zervas NT, Moskowitz MA (1981) Perivascular meningeal projections from cat trigeminal ganglia: possible pathway for vascular headache in man. Science 213:228-230

8. Nisticò G, Nappi G (1993) Locus coeruleus, an integrative station involved in the control of several vital functions. Funct Neurol 8:5-25

9. Melzack R, Casey KL (1968) Sensory, motivational and central control determinants of pain. A new conceptual model. In: Kenshalo D (ed) The skin senses. Thomas, Springfield, pp 423-439

10. Besson JM, Chauch A (1987) Peripheral and spinal mechanisms of nociception. Physiol Rev 67:67-186

11. Celesia GG (2001) Disorders of membrane channels or channelopathies. Clin Neurophysiol 112:2-18

12. MacDonald RL, Olsen RW (1994) GABAA receptor channels. Ann Rev Neurosci 17:569-602

13. Bonannno G, Ratieri M (1993) Multiple GABAB receptors. Trends Pharmacol Sci 14:259-261

14. Sandkunhler J, Jensen SJ (2000) Inhibition of nociception. In: Olesen J, Tfelt Hansen P, Welch KMA (eds) The headaches, 2nd edn. Lippincott Williams Wilkins, Philadelphia, pp 116-124
15. Segovia G, Porras A, Del Arco A, Mora F (2001) Glutametergic neurotransmission in aging: a critical prospective. Mech Ageing Dev 122:1-29

16. Welch KMA, Chabi E, Bartosh K, Meyer JS (1975) Cerebrospinal fluid gamma aminobutyric acid levels in migraine. Br Med J 3:516-517

17. Kowa H, Shimomura T, Takahashi K (1992) Platelet gamma-aminobutyric acid levels in migraine and tensiontype headache. Headache 32:229-232

18. Marukawa H, Shimomura T, Takahashi K (1996) Salivary substance P, 5hydroxytryptamine and gammaaminobutyric acid levels in migraine and tension-type headaches. Headache 36:100-104

19. Cutrer FM, Limmroth V, Moskowitz MA (1997) Possible mechanisms of valproate in migraine prophylaxis. Cephalalgia 17:93-100

20. Hering R, Kuritzky A (1992) Sodium valproate in the prophylactic treatment of migraine: a double-blind study versus placebo. Cephalalgia 12:81-84

21. Jensen R, Brink T, Olesen J (1994) Sodium valproate has a prophylactic effect in migraine without aura: a triple-blind, placebo-crossover study. Neurology 44:647-651

22. Klapper J (1997) Divalproex sodium in migraine prophylaxis: a dose-con- 
trolled study. Cephalalgia 17:103-108

23. Matthew NT, Ali S (1991) Valproate in the treatment of persistent chronic daily headache: an open label study. Headache 31:71-74

24. Di Trapani G, Mei D, Marra C, Mazza S, Capuano A (2000) Gabapentin in the prophylaxis of migraine: a doubleblind randomized placebo-controlled study. Clin Ter 151:145-148

25. D'Andrea G, Cananzi AR, Welch KMA et al (1989) Platelet levels of glutamate and aspartate in normal subjects. Stroke 2:299-300

26. Welch KMA, D'Andrea G, Tepley N, Barkley GL, Ramadan NM (1990) The concept of migraine as a state of central neuronal hyperexcitability. Neurol Clin 8:817-828

27. Mangano RM, Schwarcz R (1981) The human platelet as a model for glutamatergic neuron: Platelet uptake of L- glutamate. J Neurochem 3:1067-1076

28. D'Andrea G, Cananzi AR, Grunfeld S, Welch KMA et al (1991) Platelet

glycine, glutamate and aspartate in primary headaches. Cephalalgia

1:197-200

29. Cananzi AR, D'Andrea G, Perini F, Zamberlan F, Welch KMA (1995)

Platelet and plasma levels of glutamate and glutamine in migraine with and without aura. Cephalalgia 15:132-135

30. Lamb RJ, Leach MJ, Miller AA, Wheatley PL (1985) Anticonvulsant profile in mice of lamotrigine, a novel anticonvulsant. Br J Pharmacol 85[Suppl]:235

31. Peck AW (1994) Lamotrigine: historical background. Rev Contemp Pharmacother 5:95-105
32. Steiner TJ, Findley LJ, Yuen AWC (1997) Lamotrigine versus placebo in the prophylaxis of migraine with and without aura. Cephalalgia 17:109-112

33. D'Andrea G, Granella F, Cataldini M, Manzoni GC (1999) Effectiveness of lamotrigine in the prophylaxis of migraine with aura: a open pilot study. Cephalalgia 19:64-66

34. Lampl C, Buzarth A, Klinger D, Neumann K (1999) Lamotrigine in the prophylactic treatment migraine with aura - a pilot study. Cephalalgia 19:58-63

35. Kaube H, Herzog J, Kaufer T, Dichgans M, Diener HC (2000) Aura in some patients with familial hemiplegic migraine can be stopped by intranasal ketamine. Neurology 55:139-141 